\title{
Choice, Purchase Decision and Post-Purchase Dissonance: The Social Media Perspective
}

\author{
Kobby Mensah ${ }^{1}$, Justice Boateng Dankwah², Gilbert Kofi Mensah ${ }^{3} \&$ Judith Aku Masope-Crabbe ${ }^{4}$ \\ 1,3\&4University of Ghana, Legon, Accra, Ghana \\ 2University of Energy and Natural Resources, Sunyani, Ghana \\ kobbymensah@ug.edu.gh, jboatengdankwah@yahoo.com, mensahkofigilbert@gmail.com, \\ judithamasopecrabbe@yahoo.com
}

\begin{abstract}
Social media tools have emerged as an imperative source of information for customers. However, the relationship between information volume on social media and consumer choice quality remains blurred in literature. The study sought to examine the relationship between choice overload on social media and product choice quality, and how choice quality influences post-purchase dissonance. The study employed a positivist research paradigm and an explanatory design to examine the relationship between the various constructs. Using a purposive sampling method, Responses from 249 respondents were quantitatively analyzed. Structural equation modeling (SEM) was utilized. The outcome revealed a direct significant effect of choice overload on poor choice quality and a strong positive association between choice quality and postpurchase dissonance using social media tools. The distinctiveness of the study adds to the existing literature by extending the current understanding of post-purchase dissonance and consumer behaviour in general.
\end{abstract}

Keywords: Social media, Choice, Post-Purchase Dissonance, Choice Deficiency, Poor Choice quality.

\section{Introduction}

The last decade has witnessed the advancement of multifaceted, diverse, and intensified communications between organizations and customers through social media (SM). Social media since then has aroused a substantial amount of research interest (Li, Larimo, \& Leonidou, 2021). Studies in marketing make no exception (Karanatsiou, Misirlis \& Vlachopoulou, 2017). A reflection of the fact that consumers in this day and age spend most of their time on several social media platforms to transact high volumes of purchase-related activities in the social media space. The growing nature of the phenomenon calls for more studies across several business levels, sectors and contexts to investigate the adoption, usage, strategies and outcomes of social media to develop theory (Odoom, Anning-Dorson, \& Acheampong, 2017). Firms take advantage of social media platforms to reinforce brands, expand their geographic reach to buyers (Gao, Tate, Zhang, Chen, \& Liang, 2018) and establish a relationship with consumers (Li, Larimo, \& Leonidou, 2021). Hamilton et al. (2016) opine that consumers are also empowered to become creators, collaborators and commentators of messages on social media. The decision-making processes of consumers before product purchase have evolved over time.

It has, therefore, become imperative for both marketers and consumers to strategically employ and leverage social media to attain superior performance and competitive advantage as it continuously evolves from a marketing tool to an information search tool (Lamberton and Stephen, 2016). Twitter, Instagram, Google +, Facebook or Pinterest enables consumers to follow trends and search for product information, share consumption and lifestyle choices with their acquaintances, communicate their affiliated brands, express their brand preferences and stay close to service providers (Xu et al., 2017). Consumers perceive social media as a centre of information collation that informs their product choices (Xu et al., 2017). The success of the social media (SM) platform for the consumer decision-making is dependent on several factors such as the depth and quality of information that offer assistance to user choices and purchase decisions (Liang \& Lai, 2002). The advent of social media has permeated the core of the consumer decision-making process as consumers' purchases are widely dependent on the social media content most customers review (Alalwan et al., 2017). This is an indication that information quality on social media remains an integral part of the consumer decision-making process.

Organizations and consumers alike create content (Alalwan et al., 2017). Barger et al. (2016) argue that actions taken by consumers on SM are mostly in relation to product-related information or content posted on firms SM platforms. The content created as a result of these activities may be informative or destructive, influencing consumer choice quality and post-purchase behaviour. The exposure of customers to voluminous 
information is termed as "information overload". The quality of choice contingent on such information may be affected (Gensler et al., 2013). Information quality is imperative, as consumers rely on valuable content posted on SM to underpin their purchase decisions (Sinclaire \& Vogus, 2011). Evidence (Alalwan et al., 2017) suggests that the quality of information may influence consumers' choice and post-purchase behaviours. The social media literature has produced quite a significant amount of empirical research from consumers' (Dessart et al., 2015: Whiting \& Williams, 2013) and firms' perspectives (Odoom et al., 2017; McCann \& Barlow, 2015; Ainin et al., 2015). For instance, Zeng and Gerritsen (2014) and Knoll (2016) duly provide systematic reviews on this bourgeoning concept.

Despite its rising popularity, the literature indicates significant gaps. First, gaps exist in the extant literature, with inconclusive findings generally based on contextual dissimilarities (Knoll, 2016). As a result, continued study of the intricacies in social media usage is necessary, especially given their growing applications by consumers for business-related activities and purchasing decision-making. Second, from the consumer behaviour perspective, little evidence exists on the subject, especially from developing or emerging markets (Ainin et al., 2015). Lastly, an analysis of the literature on social media usage by consumers reveals dominance of studies from Europe, Asia and America, with pint-sized representation from Africa (Botha et al., 2011; Zeng and Gerritsen, 2014; Odoom et al., 2020). In this study, we investigate the usage of SM platforms as product information search tools for product decision-making. Consumers are now exposed to an array of brand information on the various social media platforms which could lead to information overload, hence, the current study examines information overload on SM and the nuances of the social media usage by consumers for product information, and how they affect their post-purchase behaviour (Beldad, Jong \& Steehouder, 2010).

This study, therefore, attempts to achieve two objectives; (i) Examine the relationship between information overload and quality of choice on SM (ii) and examine the relationship between Choice quality and postpurchase dissonance (PPD) on social media. The current research adds to the literature in at least three modest but pertinent ways. First, it adds to the social media and marketing literature in general. Second, it extends the current understanding of post-purchase dissonance and consumer behaviour in general by responding to the call to provide clarity on the use of SM for product information search and decision purposes. Finally, it provides businesses and managers with an empirical and contemporarily understanding of social media usage for product purchase decision-making. Having established a clear justification for this study, the paper is organized in this order; to begin; we review the relevant literature and formulate hypotheses. The methodology is explained, followed by the data analysis. The findings and implications of the study are also discussed. The study concludes with a discussion on the limitations and directions for future research.

\section{Literature Review}

The Social Media Concept: Consumer behaviour has been tremendously influenced by social media, from the need recognition stage through to information search and post-purchase behaviours such as satisfaction, dissatisfaction or customer delight statements (Voramontri, \& Klieb, 2019, Mangold \& Faulds, 2009). The definition of "social media," like many other social science terms, has struggled to reach consensus during the previous decade (Van \& Coursaris, 2013). Social media has been defined as "instruments utilized by organizations to engage in socially-based activities such as sharing photos and videos, networking within the social context, and blogging and micro-blogging"(Ala-Mutka et al., 2009). Several types of social media technologies have evolved in recent years. These technologies have been grounded on user and functionality, all playing an important role in current information access (Kietzmann, Hermken, McCarth \& Silvestre, 2011). Most firms currently advertise on varied social media pages such as LinkedIn, YouTube, Instagram, WhatsApp, Twitter and Facebook. Organizations have grown to rely on these platforms (Saxena \& Khanna, 2013).

These platforms are predominantly used to develop content, share and exchange information (Kaplan \& Haenlein, 2010; Alalwan, Rana, Dwivedi \& Algharabat, 2017). A series of studies have found that firms employ social media as a medium for promotional activities (Alalwan et al., 2017; Duffett, 2015; Singh \& Sonnenburg, 2012), establish a strong sense of recognition, and create product awareness, recall, and top of mind 
awareness of consumers. Contrasting evidence suggests that customers may not necessarily evaluate the social media information posted by firms and, as a result, are more likely to use other content on their private social media platforms (Wu, 2016; Yelba, 2010). In a content analysis of social media studies, Smith and Gallicano (2015) revealed that YouTube, Twitter, and Facebook continue to be the most popular social media platforms that many companies use to communicate with customers, generate, and share information and stories. The current study focuses on Instagram, YouTube, Facebook, Twitter as the four most popular social media technologies.

\section{Theoretical Setting and Hypotheses Development}

The EKB Model: Engel, Kollet, and Blackwell (1978) created the EKB model of consumer decision-making. The model outlines the decision-making process of consumers and how they make decisions when faced with a list of accessible options. The EKB model posits that consumers go through a series of stages before making a purchase. However, it is not incumbent that every consumer goes through all five phases of the decisionmaking process. According to the model, some consumers may skip certain stages. For instance, a consumer may recognize a need and will skip the information search and evaluation stage and continue to the purchase stage. This may sometimes be dependent on whether the need recognized is a routine problem-solving or a general need. Detailing the content of the EKB model, the model encompasses five sequential stages. According to Engel et al. (1978), a consumer goes through the five stages before deciding to make a purchase. Need identification is the first stage of the consumer in the buying decision-making process (Kardes, Cline \& Cronley, 2011). Kotler et al. (2009) suggest that need identification can either be as a result of intrinsic or extrinsic stimuli. Intrinsic stimulus is triggered by the consumer's psychological make-up whereas the extrinsic stimulus is aroused by the consumer's external environment. Hawkins and Mothersbaugh (2010) argue that the identification of need is generally influenced by factors such as reference groups, social, cultural, and environmental among other factors.

Second, need for relevant information from a variety of sources (external and internal environments). When a need is identified, the customer seeks information from several sources. There are both internal and external information sources employed. Under internal sources, a consumer may recall a product from memory. In recent times, consumers obtain most of their external sources of information from the internet (Agresta \& Bough, 2010; Hawkins \& Mothersbaugh, 2010). Consumers now appreciate the use of the internet for information search. The internet exposes them to an array of information that tends to influence their purchase decisions. Third, in determining preference, the customers' criterion is used to evaluate alternatives. At this point, customers compare and evaluate several choices based on product attributes and demands. They analyze which option will best meet their requirements (Muzondo, 2016). At the fourth stage, the consumer now decides whether to purchase or decline the purchase. After purchase, the last stage is the post-purchase evaluation. The stage where consumers assess the purchased product to ascertain whether their purchase decisions were sound. The current study found the EKB model suitable to underpin it. The model demonstrates the usefulness of the relationship that exists between consumer information search and consumer purchase decisions.

\section{Hypothesis Development}

The Choice Overload Concept: Customers are exposed to a wide range of information on social media. Since the phrase "information overload" was coined in 1970, researchers have sought to understand this problem (Toffler, 1984). Since its popularization, the phrase has regularly been used by academic scholars in their studies (Beniot and Miller, 2017). According to Beniot and Miller (2017), information overload occurs when the volume of input to a system exceeds its processing capacity. The advent of SM and other online networking sites appears to have led to a significant increase in the amount of information a user is exposed to, considerably increasing the user's likelihood of experiencing information overload. The abundance of information available on social media provides an environment ideal for information overload, particularly in the case of microblogging and related activities. It has been suggested that the majority of Twitter users say they receive too many messages, and more than half believe there is a need for a tool to filter out unnecessary tweets to make place for more important and helpful information (Bontcheva et al., 2013). Being bombarded with too much information decreases the quality of their decision making due to consumers' limited cognitive 
processing capabilities (Gross, 1964). Excessive information "(information overload)" has been found in empirical studies to have a substantial influence on users' recommendation systems (Borchers et al., 1998), work productivity (Dean \& Webb, 2011), and information systems (Borchers \& colleagues, 1998; Bawden \& Robins, 1998).

Social Media and Content Quality: In current times, social media technologies such as Facebook, Twitter and LinkedIn have substantially transformed the mode of social interactivity by offering novel avenues for engagement and information exchange. Consumers and firms are striving to efficiently incorporate information from diverse social media platforms into their daily business activities, such as product search, recruiting, sales and marketing etc (Sinclaire \& Vogus, 2011). Nevertheless, if consumers and firms are to rely on information from social media sites, they must be aware of the quality of such information. Zhou, Zhang, Yang, \& Wang (2018) question the quality of user-generated information on SM, arguing that, for information on SM to be dependable, consumers need to be aware of the quality of same. They further suggest an association between the quality of SM content and the quality of the outcome of its uses (Baeza-Yates, 2009).

Information systems (IS) and information quality (IQ) have numerous characteristics within the context of SM. This includes permanence, broad accessibility, modernity, user-friendliness and global reach (Agarwal \& Yiliyasi, 2010). According to Hajli (2018), the quality of information (QI) on social media is determined from the subjective (user) and objective (data) perspectives. Ge and Helfert (2007) describe QI as the extent of social media content confirmation and customer intent. In contrast, content quality refers to adhering to predefined and well-established norms and regulations to ensure that content on social media is free of flaws that might impede its use. According to Kushwaha (2020), internet use (such as content sharing, online communities, engagement, accessibility, and legitimacy) may impact the quality of a consumer's choice and purchase decision. In an observational study of 144 papers on social media, 89 per cent of research done supported the vital functions of social media to the customer, demonstrating the degree of dependability of SM information by consumers for decision making (Alalwan et al., 2017).

Post-Purchase Dissonance (PPD): Cognitive dissonance has been described in marketing as the anxiety associated with purchase decisions. This happens when customers are in a dilemma choosing between alternatives that have some desirable attributes (Li \& Choudhury, 2021). Cognitive dissonance can be categorized into two that is, emotional dissonance and product dissonance. Emotional dissonance is associated with psychological post-purchase discomforts such as regrets, disappointments and sadness. Product dissonance is mostly associated with the purchased product (Zeelenberg \& Pieters, 2004; Sweeney, Hausknecht, \& Soutar, 2000). The importance of cognitive dissonance theory in management decision-making has garnered more attention in academic literature in recent years (Hinojosa et al., 2017). Post-purchase dissonance (PPD) is a sort of cognitive dissonance that describes a feeling of psychological discomfort caused by conflicts between cognitive elements after purchasing a product (Keng \& Liao, 2013). This uneasiness helps customers to alleviate their bad conditions by lowering emotional tension and restoring their psychological balance (Brehm, 1956; Festinger, 1957).

According to Lee (2015), in a fiercely competitive and consumer-centric market, customers increasingly value the ability to return things as a tool to alleviate their PPD. PPD, according to Powers and Jack $(2013,2015)$, is a key psychological component that explains the influence of drivers of customers' product return behaviour. As a result, attempts to treat PPD are best served by investigating its causes. Based on the evidence from extant literature on the relationship between website information quality and PPD (Kumar \& Singh, 2019; Li and Choudhury, 2021), we postulate that information quality on SM should significantly influence PPD with Li \& Choudhury (2021) serving as a guide. In their study investigating website information quality and PPD, Li and Choudhury (2021) suggested a relationship between website information quality and PPD. Their study was limited in scope. It was only focused on the relationship between website information quality and cognitive dissonance, ignoring SM which is also believed to be an information source/search tool. Based on the afore arguments, the following hypotheses are formulated;

H1: Choice overload on social media positively influence poor product choice quality.

H2: Poor choice quality on social media positively influence post-purchase dissonance (PPD). 
Figure1: Choice Overload and Post-Purchase Dissonance; the Structural Relationship

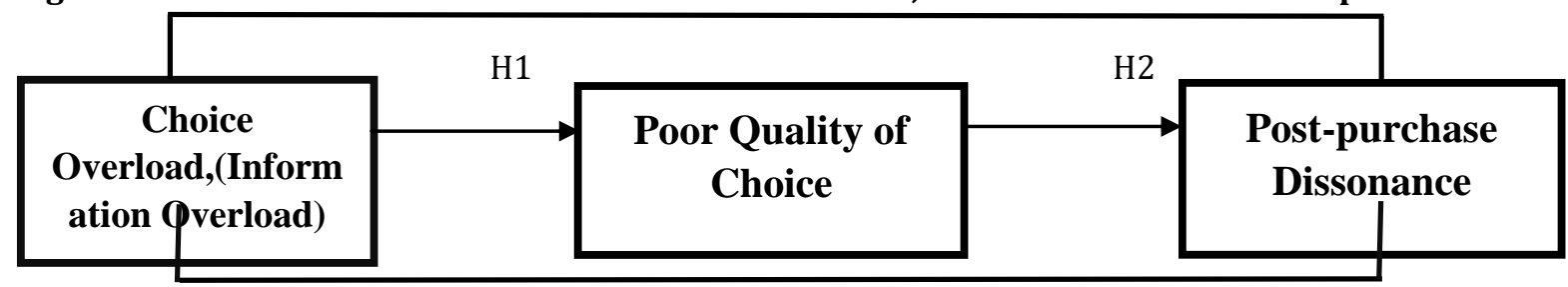

Source: Authors' Construct.

\section{Methodology}

Sample, Measures, Data Collection, and Analysis: The current study adopts a quantitative methodology. It aimed at examining the statistical relationships between choice overload, poor choice quality, and postpurchase dissonance. This was to determine the impact of choice overload on the quality of choice and decision efficiency (Creswell, 2014). The study was carried out on the campuses of the University of Ghana. The population of the study constituted all members of the university community at the time of the study. Members of the University community are believed to be a subdivision of the population that generally utilizes SM (Dankwah and Mensah, 2021; Hamade, 2013). In a similar study, to determine the impact of political message dissemination on SM on young voters, Dankwah and Mensah (2021) used members of the university community as the population. The study utilized a purposive (non-probability) sampling technique to select respondents (Malhotra \& Birks, 2007). A purposive sampling technique was deemed appropriate for the non-availability of a sampling frame for SM users within the population.

A structured questionnaire was used in the investigation (Borden \& Abbott, 2002). Scale items were adapted and anchored on a five-point Likert scale ranging from Strongly disagree to Disagree, Neutral to Agree, and Strongly agree to Strongly agree. The questionnaire was developed with two primary sections: the first section requested demographic information from respondents, and the second section concentrated on information on the variables. The sample size for the research was 249 people. The study's sample size was informed by Hair et al. (2017)'s advice that a minimum of 150 participants or more is used for quantitative social research. The researchers found it prudent to first conduct a pilot study. This was to ensure all item indicators were unambiguous and measured the constructs appropriately. Questionnaires were selfadministered as respondents were literate enough to read and understand the scale items (Creswell, 2014). SPSS Version 20.0 was utilized. Structural Equation Modeling (SEM) was used to establish relationships between the various constructs.

\section{Results and Discussion}

Sample Characteristics/Profile of Respondents: As indicated in Table 1 below, two hundred and forty-nine (294) valid responses were attained after the data was screened. The outcome showed that 128 (51.4\%) of the respondents were males and $121(48.6 \%)$ were females, which is an indication that the majority of the participants were males. The survey revealed that 193 of the participants were between the ages of 18-23, followed by $24-28$ years who represented $11.6 \%$ of the sample. This is an indication that most of the respondents were between the ages of 18 and 35, signifying that this cohort is the active users of the various social media platforms (Dankwah \& Mensah, 2021). The educational background of the participants was ascertained. 202 of the respondents were first degree holders representing $81.1 \%$ with the least respondent being diploma holders. This is an indication that the participants had an adequate educational background that enhanced their ability to understand and answer the questions appropriately.

The outcome presented the various occupational levels. The data again showed that a large portion of the respondents were students (140 representing 56.2\%), 68 representing $25.3 \%$ were employed, 50 representing $16.1 \%$ self-employed, while $5(2 \%)$ were unemployed. The study focused on the four highly patronised social media platforms which are Twitter, Instagram, YouTube and Facebook (Dankwah \& Mensah, 2021). These platforms were used by the respondent for diverse purposes. 212 of the respondents used Facebook representing 85.1\%; Twitter emerged second representing 10.8\% followed by Instagram and 
YouTube representing $2.8 \%$ and $1.2 \%$ respectively. In terms of daily usage, $74.8 \%$ agreed that they are daily users of these platforms.

Table 1: Descriptive Statistics of Respondents

\begin{tabular}{|c|c|c|c|}
\hline Profile of Respondents & Statement & Freq. & $\%$ \\
\hline \multirow[t]{3}{*}{ Gender Specifications } & Male & 128 & 51.4 \\
\hline & Female & 121 & 48.6 \\
\hline & & 249 & 100 \\
\hline \multirow[t]{6}{*}{ Age categories of Respondents } & $18-23$ & 193 & 77.5 \\
\hline & $24-28$ & 29 & 11.6 \\
\hline & $29-34$ & 23 & 9.2 \\
\hline & $35-39$ & 1 & 0.4 \\
\hline & $40+$ & 3 & 1.2 \\
\hline & & 249 & 100 \\
\hline \multirow[t]{5}{*}{ Educational Status } & Senior High & 6 & 2.4 \\
\hline & Diploma & 3 & 1.2 \\
\hline & Degree & 202 & 81.1 \\
\hline & Post-Graduate & 38 & 15.3 \\
\hline & & 249 & 100 \\
\hline \multirow[t]{6}{*}{ Employment Status } & Student & 140 & 56.2 \\
\hline & Employed & 68 & 25.3 \\
\hline & Self-employed & 41 & 16.5 \\
\hline & Unemployed & 5 & 2 \\
\hline & Retired & 0 & 0 \\
\hline & & 249 & 100 \\
\hline \multirow[t]{3}{*}{ Social Media Platform Usage } & Yes & 249 & 100 \\
\hline & No & 0 & 0 \\
\hline & & 249 & 100 \\
\hline \multirow[t]{5}{*}{ Social Media Platform Mostly Used } & Facebook & 212 & 85.1 \\
\hline & Twitter & 27 & 10.8 \\
\hline & Instagram & 7 & 2.8 \\
\hline & YouTube & 3 & 1.2 \\
\hline & & 249 & 100 \\
\hline \multirow[t]{5}{*}{ Frequency of Social Media Usage } & Daily & 217 & 74.8 \\
\hline & Once a Week & 7 & 6.2 \\
\hline & More than Once a Week & 20 & 13.9 \\
\hline & Once a Month & 1 & 3.2 \\
\hline & More than Once a Month & 6 & 1.9 \\
\hline \multirow[t]{5}{*}{ How long have you been on social media } & Less than one year & 146 & 58.6 \\
\hline & $1-5$ & 24 & 9.6 \\
\hline & $6-10$ & 30 & 12.0 \\
\hline & $11-15$ & 10 & 4.0 \\
\hline & $15+$ & 39 & 15.7 \\
\hline
\end{tabular}

Source: Field Survey. 
Confirmatory Factor Analysis (CFA): The main components of the acquired data are presented in table 2 below. Kaiser (1970) suggests that the appropriate Kaiser-Meyer-Olkin (KMO) value be at or above 0.6. The analysis revealed that KMO was 0.827 , which is higher than the recommended value. The statistical significance of Bartlett's Test of Sphericity was obtained (approx.: Chi-square= 2007.266, df. 171, sig. 0.000), which confirmed the factorization of the correlation matrix.

Table 2: KMO and Bartlett's Test Results

\begin{tabular}{lll}
\hline \multicolumn{2}{l}{ Kaiser-Meyer-Olkin Measure of Sampling Adequacy } & $\mathbf{. 8 2 7}$ \\
\hline \multirow{3}{*}{ Bartlett's Test of Sphericity } & Approx. Chi-Square & 1244.515 \\
& DF & 91 \\
& Sig. & .000 \\
\hline
\end{tabular}

Source: Field Survey.

Reliability and Validity Test: Reliability and validity of the various variables and items were tested to ensure the relevance of the adapted scales. Using a rotated component matrix, the threshold of the factor loadings were set at 0.5. To ensure the appropriateness of all loading data screening and reduction was conducted. This was to delete all poorly loaded items that might have a negative impact on the study's outcome. Table 3 depicts the result of the validity and reliability test. The outcome of the reliability test were all above the acceptable threshold as suggested by Fornell and Larcker (1981) (CR > 0.70, AVE > 0.50 , Cronbach's alphas $>0.70$ ). Further, the variables factor loadings were between 0.60 to 0.88 depicting the presence of convergent validity. Cronbach (1951) assert that Cronbach Alpha values should be 0.6 or above before a research scale is deemed reliable. Hence, all Cronbach Alpha values presented in the current study attained the recommended threshold. Reliability is the degree to which a measurement scale outcome is consistent if the construct scaling procedures are reapplied (Malhotra \& Birks, 2007).

Table 3: Validity and Reliability Test

\begin{tabular}{|c|c|c|c|c|c|c|}
\hline \multicolumn{3}{|c|}{ Principal Component Loadings } & \multicolumn{2}{|c|}{ Internal Consistencies } & \multirow[t]{2}{*}{$\begin{array}{l}\text { Construct } \\
\text { Reliability } \\
\text { (CR) }\end{array}$} & \multirow[t]{2}{*}{$\begin{array}{l}\text { Average } \\
\text { Variance } \\
\text { Extracted } \\
\text { (AVE) }\end{array}$} \\
\hline Items & Variables & Varimax & Variance Explained & Cronbach's Alphas & & \\
\hline \multirow[t]{5}{*}{ Factor 3} & ChoOv1 & 0.659 & 54.475 & 0.720 & 0.734 & 0.411 \\
\hline & ChoOv2 & 0.662 & & & & \\
\hline & ChoOv3 & 0.723 & & & & \\
\hline & ChoOv4 & 0.717 & & & & \\
\hline & ChoOv5 & 0.632 & & & & \\
\hline \multirow[t]{4}{*}{ Factor 4} & QoC1 & 0.727 & 64.892 & 0.818 & 0.821 & 0.537 \\
\hline & QoC2 & 0.841 & & & & \\
\hline & QoC3 & 0.723 & & & & \\
\hline & QoC4 & 0.779 & & & & \\
\hline \multirow[t]{5}{*}{ Factor 5} & PPD1 & 0.749 & 57.846 & 0.813 & 0.819 & 0.532 \\
\hline & PPD2 & 0.793 & & & & \\
\hline & PPD3 & 0.812 & & & & \\
\hline & PPD4 & 0.761 & & & & \\
\hline & PPD5 & 0.600 & & & & \\
\hline
\end{tabular}

Source: Field Survey. 
Discriminant Validity: The outcome of the analysis showed that there were no validity issues. As presented in Tables 3 and 4. Discriminant validity is the extent to which individual constructs are measured. The study assessed discriminant validity by adopting the Fornell-Larcker standard. This is examined by comparing the square root of the AVEs with the correlations between variables.

Table 4: Discriminant Validity

\begin{tabular}{llll}
\hline Factor & CO & QOC & PPD \\
\hline CO & $\mathbf{0 . 6 4 1}$ & & \\
QC & 0.328 & $\mathbf{0 . 7 3 0}$ & \\
PPD & 0.353 & 0.198 & $\mathbf{0 . 7 3 3}$ \\
\hline
\end{tabular}

Source: Field Survey

Final Measurement Model, Model Fit Measures, and Cut-off Criteria: The path analysis was derived after some items were deleted. Figure 2 is the graphical representation of the analysed data. Choice overload represents the independent variable whereas post-purchase dissonance is the dependent variable. Choice quality is the mediating variable between choice overload and post-purchase dissonance.

Figure 2: Final Measurement Model

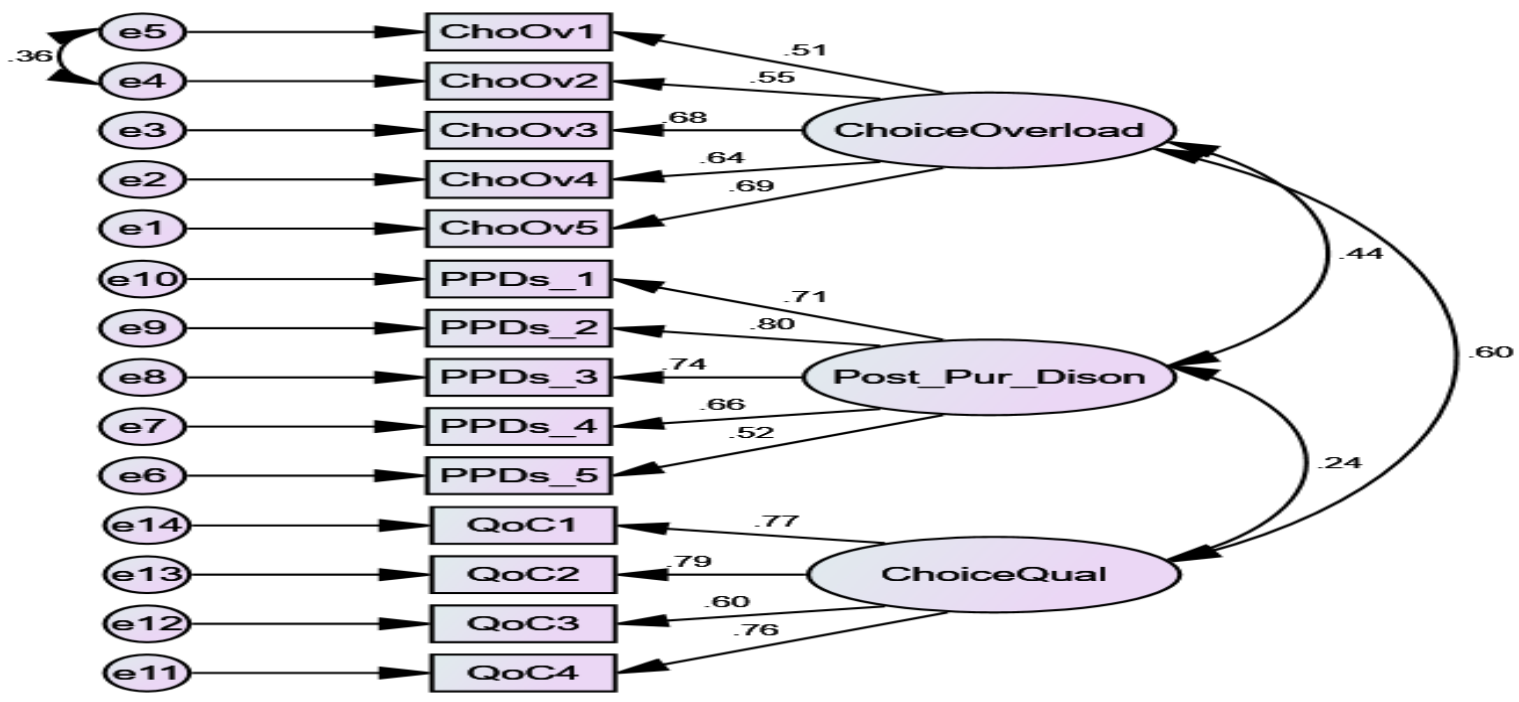

Source: Field Survey

Table 5: Table Model Fit Measures

\begin{tabular}{lll}
\hline Measure & Estimate & Threshold \\
\hline CMIN & 145.278 & -- \\
DF & 73 & - \\
CMIN/DF & 1.990 & Between 1 and 3 \\
CFI & 0.939 & $>0.95$ \\
SRMR & 0.060 & $<0.08$ \\
RMSEA & 0.063 & $<0.06$ \\
PClose & 0.074 & $>0.05$ \\
\hline
\end{tabular}

Source: Field Survey 
Table 6: Cut-off Criteria

\begin{tabular}{lll}
\hline Measure & Terrible & Acceptable \\
\hline CMIN/DF & $>5$ & $>3$ \\
CFI & $<0.90$ & $<0.95$ \\
SRMR & $>0.10$ & $>0.08$ \\
RMSEA & $>0.08$ & $>0.06$ \\
PClose & $<0.01$ & $<0.05$ \\
\hline
\end{tabular}

Source: Hu and Bentler (1999)

Hypotheses testing Using Structural Equation Model: The study formulated two hypotheses (H1 and H2) which analysed the cause-effect between the constructs. H1 analysed the link amid choice overload and quality of choice. Further, the second hypothesis (H2) assessed the quality of choice on post-purchase dissonance. Figure 3 presents the structural equation modelling of the hypothesised relationships.

Figure 3: Structural Equation Model

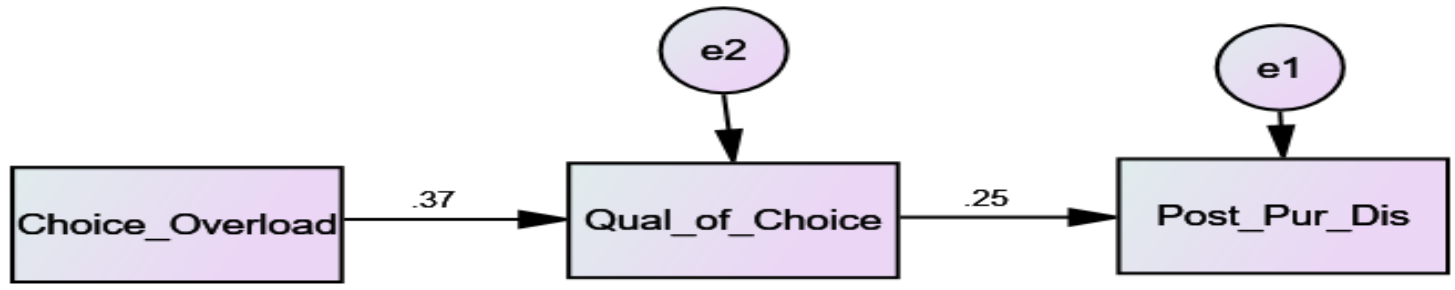

Source: Field Survey/Data Analysis

Summary of Structural Equation Modelling Result: The fit indices of the structural model were examined. The result showed that $\mathrm{SRMR}=0.034<0.08, \mathrm{CMIN}=4.597$, $\mathrm{RMSEA}=0.022<0.06, \mathrm{NFI}=.975, \mathrm{GFI}=.995, \mathrm{IFI}=.997$, RFI=.905. The summary of the result has been reported in table 4.7 below.

Table 7: Structural Equation Modeling Outcome

\begin{tabular}{lllllll}
$\begin{array}{l}\text { Relationship } \\
\text { (Hypothesis) }\end{array}$ & $\begin{array}{l}\text { Construct } \\
\text { Structural } \\
\text { Relationship }\end{array}$ & $\begin{array}{l}\boldsymbol{\beta} \\
\text { Estimate }\end{array}$ & SE & $\begin{array}{l}\text { t- } \\
\text { Values }\end{array}$ & $\begin{array}{l}\mathbf{p}- \\
\text { Values }\end{array}$ & Outcome \\
\hline $\begin{array}{l}\text { Effect of Choice Overload on Choice Quality } \\
\text { Choice_Overload---> }\end{array}$ & & & & & \\
Hypothesis 1: & $\begin{array}{l}\text { Post_Purchase_Dissonance } \\
\text { The mediating effect of choice quality }\end{array}$ & 0.368 & 0.06 & 6.228 & $* * *$ & Supported \\
$\begin{array}{l}\text { Hypothesis 2: Mediation } \\
\text { Effect }\end{array}$ & $\begin{array}{l}\text { Choice_Quality--- } \\
\text { Indirect Effect }\end{array}$ & 0.247 & 0.55 & 4.008 & $* * *$ & Supported \\
\hline
\end{tabular}

Source: Field Survey.

Discussion of Findings

The first hypothesis investigated the effect of choice overload on decision quality. The results demonstrated a significant effect of choice overload on decision quality with $\mathrm{H} 1: \beta=0.368, t=6.228, \mathrm{p}=0^{* * *} 0.05$. This suggests that the abundance of information on social media has an impact on the quality of consumer choice. For example, discussions generated from Facebook and concurrently shared information has a significant impact on consumers' ability to make a quality choice of content to rely on (Eskisu et al., 2017). This outcome is 
consistent with prior studies that found information overload to have an influence on choice quality (Nguyen et al., 2019; Taylor, Lewin \& Strutton, 2011). The second hypothesis examined the relationship between the quality of choice consumers make and post-purchase dissonance. The finding showed a negative but significant relationship between the variables i.e. quality of choice and post-purchase dissonance (H2: $t=$ $4.008, \beta=0.247, \mathrm{p}=* * *<0.05$ ), confirming the second hypothesis.

This outcome reveals that the quality of choice consumers make on social media minimizes post-purchase dissonance. Thus, when information accessed on social media are moderate and clear, the consumer is able to make quality choices that negatively affect their post-purchase dissonance. This is to state that, choosing a good product lessens post-purchase dissonance. This Finding again is consistent with earlier studies (Duffett, 2015; Lee \& Hong, 2016) which found a positive correlation between quality information and consumers' perception of brands. This study concludes that creative and informative content on social media underpins consumer decision-making. Almeida-Santana and Moreno-Gil (2017) affirm this assertion by reporting that social media advertising content should be worthwhile and relevant to influence consumers' behaviour and decision. It is pertinent that marketing managers improve their interactivity with customers via Facebook and Twitter to enhance their decision-making.

\section{Implications and Recommendations}

This study, in several ways, adds to the marketing and social media literature. It extends the current understanding of post-purchase dissonance and consumer behaviour in general by responding to the call to provide clarity on social media usage for purchase information search and decision purposes. It again explores to unearth the nuances of the effect of choice overload on consumer choice quality. It sets the agenda for understanding some assumptions underlying the increasing use of social media in Africa for information search and business purposes in general. The market's heterogeneity in Sub-Saharan Africa reflects some of the peculiarities associated with emerging markets. As a result, they provide fertile ground for novel insights in the marketing literature, with some research deviating dramatically from observations of industrialized markets (Odoom \& Kosiba, 2020). Using data from a Sub-Saharan African nation, therefore, supplements the literature with (UN) familiar evidence for potential corroborations (Dahlberg et al., 2015). The study, therefore, contributes to extant literature with empirical evidence that progresses our current understanding of the use of SM as a content search tool by consumers for making a purchase decision in emerging/lessdeveloped economies.

The study, also, gives marketing practitioners insight into the use of SM as an information search tool by consumers to make a purchase decision by providing empirical evidence on the subject matter. We, therefore, make the following recommendations; (1) organisations that employ social media platforms to promote their products emphasise developing content to influence consumers that make decisions based on social media information. (2) Marketing and sales managers must also improve their engagement and interactivity with their customers on social media to improve their purchase decision-making processes and successfully manage post-purchase behaviours. (3) Bearing in mind the extent of social media impact in shaping consumers choice, firms can consider celebrity endorsement and social media influencers to improve consumers consideration set, thus strengthening the quality of choice and ensuring effective management of post-purchase behaviours.

\section{Limitations and Future Research Avenues}

Whereas this research contributes greatly to SM communication literature, it is not without limitations. However, the limitations do not invalidate the outcome of the study. The constraints of the study, therefore, provide avenues for future research. First, the research utilized a purposive sampling technique. This is a non-probability sampling technique capable of producing a sampling bias. Second, the study did not consider the moderating roles of purchase involvement and demographic characteristics such as age and gender which may be capable of influencing dissonance and social media usage as an information search tool. Future studies may consider these moderating variables. Finally, four social media technologies (Twitter, YouTube, Facebook, and Instagram) were used concurrently in this study. As a result, we recommend that future research explore using specific social media networks. This will reveal the intricacies of how each of them is 
used by consumers and provide specificity to the results' applicability. In the future, the social media content of individual organizations may be examined to restrict the findings and give them a more definite meaning to organizations.

Declaration: This study received no support or funding from any entity or organization. We, therefore, declare that there is no issue regarding conflict of interest.

Data Availability Statement: The datasets generated and/or analyzed during the current study are available from the corresponding author on reasonable request.

Consent to Participate: The consent of all respondents was obtained before gathering the data for the study.

Author Contribution: All authors contributed to the success of this article.

\section{References}

Agarwal, N. \& Yiliyasi, Y. (2010, November). Information quality challenges in social media. In ICIQ.

Agresta, S. \& Bough, B. B. (2010). Perspectives on social media marketing. Nelson Education.

Ainin, S., Parveen, F., Moghavvemi, S., Jaafar, N. I. \& Shuib, N. L. M. (2015). Factors influencing the use of social media by SMEs and its performance outcomes. Industrial Management \& Data Systems.

Alalwan, A. A., Rana, N. P., Dwivedi, Y. K. \& Algharabat, R. (2017). Social media in marketing: A review and analysis of the existing literature. Telematics and Informatics, 34(7), 1177-1190.

Ala-Mutka, K., Broster, D., Cachia, R., Centeno, C., Feijóo, C., Haché, A. \& Punie, E. Y. (2009). The Impact of Social Computing on the EU Information Society and Economy (2009). European Commission Joint Research Centre Institute for Prospective Technological Studies: Seville (Spain).

Almeida-Santana, A. \& Moreno-Gil, S. (2017). New trends in information search and their influence on destination loyalty: Digital destinations and relationship marketing. Journal of destination marketing \& management, 6(2), 150-161.

Baeza-Yates, R. (2009, April). User-generated content: how good is it? In Proceedings of the 3rd workshop on Information Credibility on the web (pp. 1-2).

Barger, V., Peltier, J. W. \& Schultz, D. E. (2016). Social media and consumer engagement: a review and research agenda. Journal of Research in Interactive Marketing.

Beldad, A., De Jong, M. \& Steehouder, M. (2010). How shall I trust the faceless and the intangible? A literature review on the antecedents of online trust. Computers in human behavior, 26(5), 857- 869.

Bontcheva, K., Gorrell, G. \& Wessels, B. (2013). Social media and information overload: Survey results. arXiv preprint arXiv:1306.0813.

Botha, E., Farshid, M. \& Pitt, L. (2011). How sociable? An exploratory study of university brand visibility in social media. South African Journal of Business Management, 42(2), 43-51.

Creswell, J. W. (2014). Qualitative, quantitative and mixed methods approach. Sage.

Cronbach, L. J. (1951). Coefficient alpha and the internal structure of tests. Psychometrika, 16(3), 297-334.

Dankwah, J. B. \& Mensah, K. (2021). Political marketing and social media influence on young voters in Ghana. SN Social Sciences, 1(6), 1-19.

Del Hawkins, I. \& L Mothersbaugh, D. (2010). Consumer Behaviour Building Marketing Strategy.

Dessart, L., Veloutsou, C. \& Morgan-Thomas, A. (2015). Consumer engagement in online brand communities: a social media perspective. Journal of Product \& Brand Management.

Duffett, R. G. (2015). Facebook advertising's influence on intention-to-purchase and purchase amongst Millennials. Internet Research.

Engel, J. F., Kollat, D. T. \& Blackwell, R. D. (1978). Consumer behavior, 3rd ed. Hinsdale, IL: Dryden

Eşkisu, M., Hoşoğlu, R. \& Rasmussen, K. (2017). An investigation of the relationship between Facebook usage, Big Five, self-esteem and narcissism. Computers in Human Behavior, 69, 294-301.

Fornell, C. \& Larcker, D. F. (1981). Structural equation models with unobservable variables and measurement error: Algebra and statistics.

Gao, H., Tate, M., Zhang, H., Chen, S. \& Liang, B. (2018). Social media ties strategy in international branding: An application of resource-based theory. Journal of International Marketing, 26(3), 45-69. 
Ge, M. \& Helfert, M. (2007). A review of information quality research-develop a research agenda. In Paper presented at the International Conference on Information Quality 2007.

Gensler, S., Völckner, F., Liu-Thompkins, Y. \& Wiertz, C. (2013). Managing brands in the social media environment. Journal of interactive marketing, 27(4), 242-256.

Hajli, N. (2018). Ethical environment in the online communities by information credibility: a social media perspective. Journal of Business Ethics, 149(4), 799-810.

Hamade, S. N. (2013). Perception and use of social networking sites among university students. Library Review.

Hamilton, M., Kaltcheva, V. D. \& Rohm, A. J. (2016). Social media and value creation: the role of interaction satisfaction and interaction immersion. Journal of Interactive Marketing, 36, 121-133.

Hinojosa, A. S., Gardner, W. L., Walker, H. J., Cogliser, C. \& Gullifor, D. (2017). A review of cognitive dissonance theory in management research: Opportunities for further development. Journal of Management, 43(1), 170-199.

Kaiser, H. F. (1970). A second generation little jiffy. Psychometrika, 35(4), 401-415.

Kaplan, A. M. \& Haenlein, M. (2010). Users of the world, unite! The challenges and opportunities of Social Media. Business Horizons, 53(1), 59-68.

Karanatsiou, D., Misirlis, N. \& Vlachopoulou, M. (2017). Bibliometrics and altmetrics literature review: Performance indicators and comparison analysis. Performance Measurement and Metrics.

Kardes, F. R., Cline, T. W. \& Cronley, M. L. (2011). Consumer behaviour: Science and practice.

Kietzmann, J. H., Hermkens, K., McCarthy, I. P. \& Silvestre, B. S. (2011). Social media? Get serious! Understanding the functional building blocks of social media. Business Horizons, 54(3), 241-251.

Knoll, J. (2016). Advertising in social media: a review of empirical evidence. International Journal of Advertising, 35(2), 266-300.

Kumar, v. \& Singh, n. (2019). Post-purchase experience of consumers in life insurance policies: an empirical study. Skyline business journal, 14(2).

Kushwaha, B. P. (2020). Implementing Sustainable Marketing through Integration of Employees, Customers and Technology. PalArch's Journal of Archaeology of Egypt/Egyptology, 17(6), 2089-2099.

Lamberton, C. \& Stephen, A. T. (2016). A thematic exploration of digital, social media, and mobile marketing: Research evolution from 2000 to 2015 and an agenda for future inquiry. Journal of Marketing, 80(6), 146-172.

Lee, J. \& Hong, I. B. (2016). Predicting positive user responses to social media advertising: The roles of emotional appeal, informativeness, and creativity. International Journal of Information Management, 36(3), 360-373.

Li, F., Larimo, J. \& Leonidou, L. C. (2021). Social media marketing strategy: definition, conceptualization, taxonomy, validation, and future agenda. Journal of the Academy of Marketing Science, 49(1), 51-70.

Li, M. \& Choudhury, A. H. (2021). Using website information to reduce post-purchase dissonance: A mediated moderating role of perceived risk. Psychology \& Marketing, 38(1), 5669.

Liang, T. P. \& Lai, H. J. (2002). Effect of store design on consumer purchases: an empirical study of online bookstores. Information \& management, 39(6), 431-444.

Liao, T. H. \& Keng, C. J. (2013). Online shopping delivery delay: Finding a psychological recovery strategy by online consumer experiences. Computers in Human Behaviour, 29(4), 1849-1861.

Malhotra, N. K. \& Birks, D. (2007). Marketing Research, an Applied Approach, European Edition.

Mangold, W. G. \& Faulds, D. J. (2009). Social media: The new hybrid element of the promotion mix. Business Horizons, 52(4), 357-365.

McCann, M. \& Barlow, A. (2015). Use and measurement of social media for SMEs. Journal of small business and enterprise development.

Muzondo, N. (2016). Modelling consumer behaviour conceptually through the seven Ps of marketing: A revised theoretical generic consumer stimulus-response model.

NGUYEN, V. \& BANG, J. (2019). E-tailing \& brand communication in facebook: Comparing Germans and Koreans. The Journal of Distribution Science, 17(8), 99-106.

Odoom, R., Anning-Dorson, T. \& Acheampong, G. (2017). Antecedents of social media usage and performance benefits in small-and-medium-sized enterprises (SMEs). Journal of Enterprise Information Management. 
Odoom, R., Anning-Dorson, T. \& Acheampong, G. (2017). Antecedents of social media usage and performance benefits in small-and-medium-sized enterprises (SMEs).Journal of Enterprise Information Management.

Osei, B. A. \& Abenyin, A. N. (2016). Applying the Engell-Kollat-Blackwell model in understanding international tourists' use of social media for travel decisions to Ghana. Information Technology \& Tourism, 16(3), 265-284.

Powers, T. L. \& Jack, E. P. (2015). Understanding the causes of retail product returns. International Journal of Retail \& Distribution Management.

Saxena, A. \& Khanna, U. (2013). Advertising on social network sites: A structural equation modelling approach. Vision, 17(1), 17-25.

Sinclaire, J. K. \& Vogus, C. E. (2011). Adoption of social networking sites: an exploratory adaptive structuration perspective for global organizations. Information Technology and Management, 12(4), 293-314.

Singh, S. \& Sonnenburg, S. (2012). Brand performances in social media. Journal of interactive marketing, 26(4), 189-197.

Sweeney, J. C., Hausknecht, D. \& Soutar, G. N. (2000). Cognitive dissonance after purchase: A multidimensional scale. Psychology \& Marketing, 17(5), 369-385.

Taylor, D. G., Lewin, J. E. \& Strutton, D. (2011). Friends, fans, and followers: do ads work on social networks: how gender and age shape receptivity. Journal of advertising research, 51(1), 258-275.

Toffler, A. (1984). Previews and premises. Black Rose Books Limited.

Van Osch, W. \& Coursaris, C. K. (2013, January). Organizational social media: A comprehensive framework and research agenda. In 2013 46th Hawaii International Conference on System Sciences (pp. 700707). IEEE.

Voramontri, D. \& Klieb, L. (2019). Impact of social media on consumer behaviour. International Journal of Information and Decision Sciences, 11(3), 209-233.

Whiting, A. \& Williams, D. (2013). Why people use social media: a uses and gratifications approach. Qualitative market research: an international journal.

Xu, A., Liu, Z., Guo, Y., Sinha, V. \& Akkiraju, R. (2017, May). A new Chabot for customer service on social media. In Proceedings of the $2017 \mathrm{CHI}$ conference on human factors in computing systems, 3506-3510.

Zeelenberg, M. \& Pieters, R. (2004). Beyond valence in customer dissatisfaction: A review and new findings on behavioural responses to regret and disappointment in failed services. Journal of Business Research, $57(4), 445-455$.

Zeng, B. \& Gerritsen, R. (2014). What do we know about social media in tourism? A review. Tourism management perspectives, 10, 27-36.

Zhou, L., Zhang, D., Yang, C. C. \& Wang, Y. (2018). Harnessing social media for health information management. Electronic commerce research and applications, 27, 139-151. 